\title{
Kounis Syndrome: Case Report in Goiânia/BR
}

\author{
Marília Pereira, ${ }^{10}$ Gabriela Lima Vieitas, ${ }^{10}$ Anna Ilona Hunkar Freitas, ${ }^{10}$ Karoly Gyula Olivas Hunkar ${ }^{2}$ \\ UniFOA - Centro Universitário de Volta Redonda, ${ }^{2}$ Volta Redonda, RJ - Brazil \\ Hospital Santa Maria, ${ }^{2}$ Goiânia, GO - Brazil
}

\begin{abstract}
22-year-old male patient with no heart disease, who was given an ambulatory medication with analgesics due to an acute renal crisis. After the drug administration, the patient presented dyspnea, cyanosis, and hemoptysis. There was suspicion of anaphylactic shock, which was treated, but there was no improvement in the clinical condition. The patient was referred to the Intensive Care Unit, where tests were performed showing elevated cardiac enzymes and Immunoglobulin E and Computed Tomography of Thoracic revealed alveolar hemorrhage. He developed clinical worsening and died after sepsis. The final diagnosis was of kounis syndrome due to the hypersensitivity reaction to the analgesics introduced in the patient, generating an acute coronary syndrome (ACS). The purpose of this case report was to highlight a syndrome that is little reported because it is not part of the differential diagnosis routines of ACS, but it generates important complications.
\end{abstract}

\section{Introduction}

Kounis syndrome (referred here as SK) is consisted of an acute coronary syndrome but despite the usual atherosclerosis etiology has its origin in anaphylactic or anaphylactoid allergic reactions. It was described in 1991, also having as variants vasospastic angina of allergic etiology, allergic myocardial infarction, and stent thrombosis - if occlusive thrombus infiltrated by eosinophils and/or mastocytes.$^{1-3}$

\section{Keywords}

Heart/drug effects; Biomarkers; Immunoglobulins; Kounis Syndrome; Acute Coronary Syndrome; Sepsis; Hemorrhage; Diagnostic Imaging; Tramadol.
The syndrome is caused by inflammatory mediators such as histamine, platelet activating factor, arachidonic acid products, neutral proteases, cytokines, and chemokines that trigger a cascade that results in the activation of inflammatory cells. This set of mediators, in turn, feed a vicious cycle with the release of more mediators. All of this leads to coronary vasospasm justifying its clinic of an acute coronary syndrome. ${ }^{3}$

To date, several triggering factors of such a hypersensitivity reaction have been described and their number continues to grow. In addition, factors like medicines and food can be highlighted. ${ }^{3}$ Among the drugs, several classes frequently used in clinical practice are triggers of SK, such dipyrone, etomidate, beta-lactam antibiotics, trimetafan, non-steroidal anti-inflammatories, antineoplastics, contrasts, corticosteroids, antiseptics, muscle relaxants, proton pump inhibitors, thrombolytics and anticoagulants, among others. ${ }^{4}$

Apparently, SK is not a rare syndrome, but there is little medical knowledge in general due to lost cases and undiagnosed and/or reported cases. Although there are no large prospective studies evaluating its exact incidence and prevalence, it is distributed in all age groups, races and geographic locations. ${ }^{3}$

Given the shortage of literature on SK, this report contributes to the dissemination of knowledge about such pathology. Thus, its recognition by the medical community may be more effective causing an increase in the number of reported cases, its description in the literature and most important, the management of patients presenting such condition.

\section{Case Report}

A 22-year-old male patient was admitted to the Santa Maria Hospital in Goiânia-GO on 10/19/2017,

Mailing Address: Anna Ilona Freitas

Av. Paulo Erlei Alves Abrantes, 1325. Postal Code: 27240-560, Volta Redonda, RJ - Brazil.

E-mail: anna.ilona@uol.com.br 
complaining of severe low back pain on the right associated with nausea and vomiting. He reported being under treatment for epilepsy. During physical examination, he was in good general condition, eupneic, pale $(++/ 4+)$, sweaty, acyanotic and afebrile. Tramadol hydrochloride $100 \mathrm{mg}$ was prescribed, without clinical improvement, then he was medicated with 1 ampoule of scopolamine + butylbromide + dipyrone and $40 \mathrm{mg}$ of tenoxicam intravenously (IV). After administration, the patient presented dyspnea, profuse sweating, cold skin, cyanotic extremities, and an episode of hemoptysis, being administered intravenously hydrocortisone 500mg, promethazine and adrenaline. The patient denied fever, cough or previous respiratory distress, as well as the use of anabolic/steroids or narcotics.

The patient evolved to respiratory failure and was transferred to the Intensive Care Unit. Upon admission to the ICU, the patient presented chest pain, tachypnea, tachycardia, hypotension, diffusely decreased vesicular murmur in pulmonary auscultation, $\mathrm{O} 2$ saturation of $81 \%$ coupled to the oxygen mask. Volume replacement, adrenaline (1amp), dimenhydrinate (1 amp) and promethazine (1 amp) were initiated.

Laboratory tests for admission showed leukocytosis $\left(26,300\right.$ leukocytes $\left./ \mathrm{mm}^{3}\right)$, neutrophilia (13\% of neutrophils), C Reactive protein $4.2 \mathrm{mg} / \mathrm{L}$, DHL 242 U/L, Troponin T 0.138 ng/ml, CPK 120 U/L, CKMB $38 \mathrm{U} / \mathrm{L}$, D-dimer $2.6 \mathrm{mg} / \mathrm{mL}$, Immunoglobulin E $177 \mathrm{IU} / \mathrm{mL}$. Among the requested imaging tests, the electrocardiogram and echocardiogram showed no alteration, chest CT scan showed alveolar hemorrhage.

The patient evolved with worsening of respiratory mechanics and orotracheal intubation was performed while clinical support was maintained. On the second day of hospitalization, the patient presented CPK 708 $\mathrm{U} / \mathrm{L}, \mathrm{CKMB} 34.5 \mathrm{U} / \mathrm{L}$, lactate of $3.2 \mathrm{mmol} / \mathrm{L}$ and CRP 143.3 $\mathrm{mg} / \mathrm{L}$. On the third day, myocardial injury biomarkers began to decrease until they normalized.

The patient had a clinic follow up with several specialties in the ICU due to pauci-immune pulmonary capillaritis, pneumonia and the Acute Respiratory Distress Syndrome. Treatment included pulse therapy with solumedrol, immunosuppressive and plasmapheresis, in addition to antibiotic therapy and intensive care. Due to hemodynamic instability, the patient evolved into sepsis and cardiorespiratory arrest and did not answer to any resuscitation maneuvers. He died after 19 days of hospitalization.

\section{Discussion}

Kounis syndrome, also known as allergic angina, can be defined as an acute coronary syndrome caused by vasospasm, secondary to a hypersensitivity reaction. As it is little known, it is not part of most differential diagnostic routines for acute coronary syndromes and for this reason, it is often underdiagnosed. The risk factors involve previous history of atopy, hypertension, smoking, diabetes and dyslipidemia, and the main triggers are medications and insect bites. (Table 1) ) $^{5,6}$

The hypersensitivity reaction culminates in mast cell degranulation, releasing proteases and vasoactive mediators. Among these substances, the main one is histamine, which is a potent

Table 1 - Drugs with the possibility of causing Kounis Syndrome

\begin{tabular}{ll} 
Painkillers & Dipyrone \\
\hline Anesthetics & Etomidate \\
\hline
\end{tabular}

\begin{tabular}{lc}
\hline Antibiotics & $\begin{array}{c}\text { Ampicillin, ampi/sulbactam, } \\
\text { amoxicillin, amicacin, cefazoline, } \\
\text { cefoxitin, cefuroxim, penicillin, } \\
\text { vancomycin, ciprofloxacin }\end{array}$ \\
\hline Anticholinergics & Trimetafan \\
\hline NSAIDs & Ciclofenac, naproxen, ibuprofen \\
\hline Antineoplastic & interferon \\
\hline Contrasts & $\begin{array}{c}\text { Indigotindisulfonate, lohexol, } \\
\text { loxaglato }\end{array}$ \\
\hline Corticosteroids & Betamethasone, hydrocortisone \\
\hline Skin Disinfectants & Chlorhexidine, povidone iodine \\
\hline Puscle relaxants & Cisatracurium, rocuronium \\
\hline
\end{tabular}

Thrombolytics and $\quad$ Heparin, streptokinase, urokinase,
anticoagulants lepirudine, hirudine, bivalirudine

Alopurinol, enalapril, smolol, insulin, protamine, iodine, part of nicotine, mesalamine, bupropion, tetanus toxoid

Source: Ceped, Herrejon, Aguirregabiria ${ }^{4}$ 
vasoconstrictor. The vasospasm provided by histamine justifies the symptomatology of this syndrome. In addition, histamine lowers diastolic blood pressure, increases intimal thickening and platelet activation. Furthermore, studies suggest the possibility that mastocytes present near thrombi may destabilize and cause thrombus maturation due to the anticoagulant effect of fibrinogen degradation. ${ }^{7}$

There are three types of presentation already described: type I, the more frequent one, is found in patients without predisposition to coronary artery disease whose arteries are normal as the patient reported in the case: young and without risk factors. In type II, patients have quiescent atheroma, which, added to the sudden allergic condition, leads to angina and acute myocardial infarction. Type III, on the other hand, is related to drug-eluting stent thrombosis, late to stent placement by hypersensitivity reaction to nickel alloys, drugs and polymers present in the device. ${ }^{7}$

The clinical condition is characterized by chest pain - the most common manifestation - palpitations and shortness of breath, followed several times by hives, wheezing and skin reactions. Such allergic signs, however, are not mandatory and dyspnea was observed in the reported patient, accompanied by nausea and vomiting. Common evolution is an acute pulmonary edema, which may explain hemoptysis presented by the patient, and severe anaphylactic reaction, which lead to hypotension and shock. Differential diagnosis is made with other acute coronary syndromes, such as stable angina, unstable angina, acute myocardial infarction, Takotsubo, stressinduced cardiomyopathy, hypersensitivity myocarditis, and coronary vasculopathy. ${ }^{6-8}$

The diagnosis is clinical but laboratory, echo, and electrocardiographic tests can complement it. As histamine has a short half-life, its low rates do not exclude diagnosis, as well as low IgE. Cardiac troponins I or T and myocardial injury biomarkers (CK and CK-MB) are important in the diagnosis of myocardial injury with the patient elevated Troponin $\mathrm{T}$ by 4.6 times the normal combined with an increase in CK and CK-MB. The electrocardiogram may present characteristic changes of ischemia and the ST segment elevation is the most common. However, the electrocardiogram will only be altered in the presence of vasospasm associated with pain. Therefore, it is possible that such a finding would not appear on the exam, as occurred in the case presented. ${ }^{5,9}$

The therapeutic approach should prioritize the resolution of anaphylaxis using corticosteroids, antihistamines, and calcium channel blockers. Despite being an acute coronary syndrome, medications such as aspirin, nitroglycerin, beta-blockers, and epinephrine should not be used due to the risks of clinical deterioration being greater than the benefits. The prognosis of Kounis syndrome is good although it can lead to serious complications. ${ }^{8,10}$

\section{Conclusion}

After analyzing the case report, we identified that the patient presented Kounis Syndrome, a rare condition that is difficult to diagnose and justifies the need to report and discuss the topic. Such a syndrome is probably underdiagnosed in the medical practice and its suspicion should be raised in patients with a history of allergy, in patients with acute drug allergy on suspicion of acute ischemic syndrome, or the ones who have allergies to implanted devices. If suspected, medications such as nitroglycerin, beta-blockers and epinephrine should be avoided.

\section{Author Contributions}

Acquisition of data: Hunkar KGO. Analysis and interpretation of the data: Freitas AIH. Writing of the manuscript: Pereira M. Critical revision of the manuscript for intellectual content: Vieitas GL.

\section{Potential Conflict of Interest}

No potential conflict of interest relevant to this article was reported.

\section{Sources of Funding}

There were no external funding sources for this study.

\section{Study Association}

This study is not associated with any thesis or dissertation work.

\section{Ethics Approval and Consent to Participate}

This study was approved by the Ethics Committee of the Hospital Estadual Geral de Goiânia Dr. Alberto Rassi - HGGl under the protocol number 15449119.7.0000.0035. All the procedures in this study were in accordance with the 1975 Helsinki Declaration, updated in 2013. Informed consent was obtained from all participants included in the study. 


\section{References}

1. Dauvergne C; Araya M; Abufhele A. Coronary spasm secondary to allergic reaction or Kounis syndrome: Clinical case. Rev méd Chile. 2009; 137(6): 811-4.

2. Kounis NG. Kounis syndrome: an update on epidemiology, pathogenesis, diagnosis, and therapeutic management. Chin Chem Lab. Med. 2016; 54(10): 1545-59.

3. Kounis NG; Zavras GM. Histamine-induced coronary artery spasm: the concept of allergic angina. Br J Clin Pract. 1991;45(2):121-8.

4. Cepeda PR; Herrejon EP; MMR aguirregabiria. Kounis syndrome. Med Intensive. 2012. 36(5):358-64.

5. Abdelghany M; Subedi R; Shah S; Kozman H. Kounis syndrome: A review article on epidemiology, diagnostic findings, management, and complications of allergic acute coronary syndrome. Int J Cardiol. 2017;232:1-4.
6. Juste JFM; Garces TR; RG enguita; Blasco PC; Ja Trallero. Cardiac complications em síndrome de Kounis type I inferred by methamizol. Rev Bras. Anestesiol. 2016. 66(2):194-6.

7. Hangouche AJE; Lamliki O; Oukerraj L; Dakka T; Doghmi N; Zarzur J; Cherti M. Kounis syndrome induced by oral intake of aspirin: case report and literature review. Pan Afr Med J. 2018.30:301.

8. Francisco J; Vargas G; Javier M; Sánchez-Calderón P; Ortiz C; Porro $\mathrm{R}$; et al. Scardiogenic hock secondary to methamizol-induced Kounis syndrome. Rev Esp Cardiol.2012;65:1138-9.

9. Sánchez VO; Roca LC; Moreno ADP. Intraoperative "Kounis syndrome" that improved electrocardiography changes and hemodynamic situation after administering nitroglycerine. Rev Bras Anestesiol. 2014;64(4):281-5.

10. Rodrigues MCL; Coelho D; Granja G. Drugs that may provoke Kounis Syndrome. Rev Bras Anestesiol. 2013;63(5):426-8. 